Document downloaded from:

http://hdl.handle.net/10251/141953

This paper must be cited as:

Noverques-Medina, A.; Verdú Martín, GJ.; Juste Vidal, BJ.; Sancho, M. (02-2). Experimental radon exhalation measurements: Comparison of different techniques. Radiation Physics and Chemistry. 155:319-322. https://doi.org/10.1016/j.radphyschem.2018.08.002

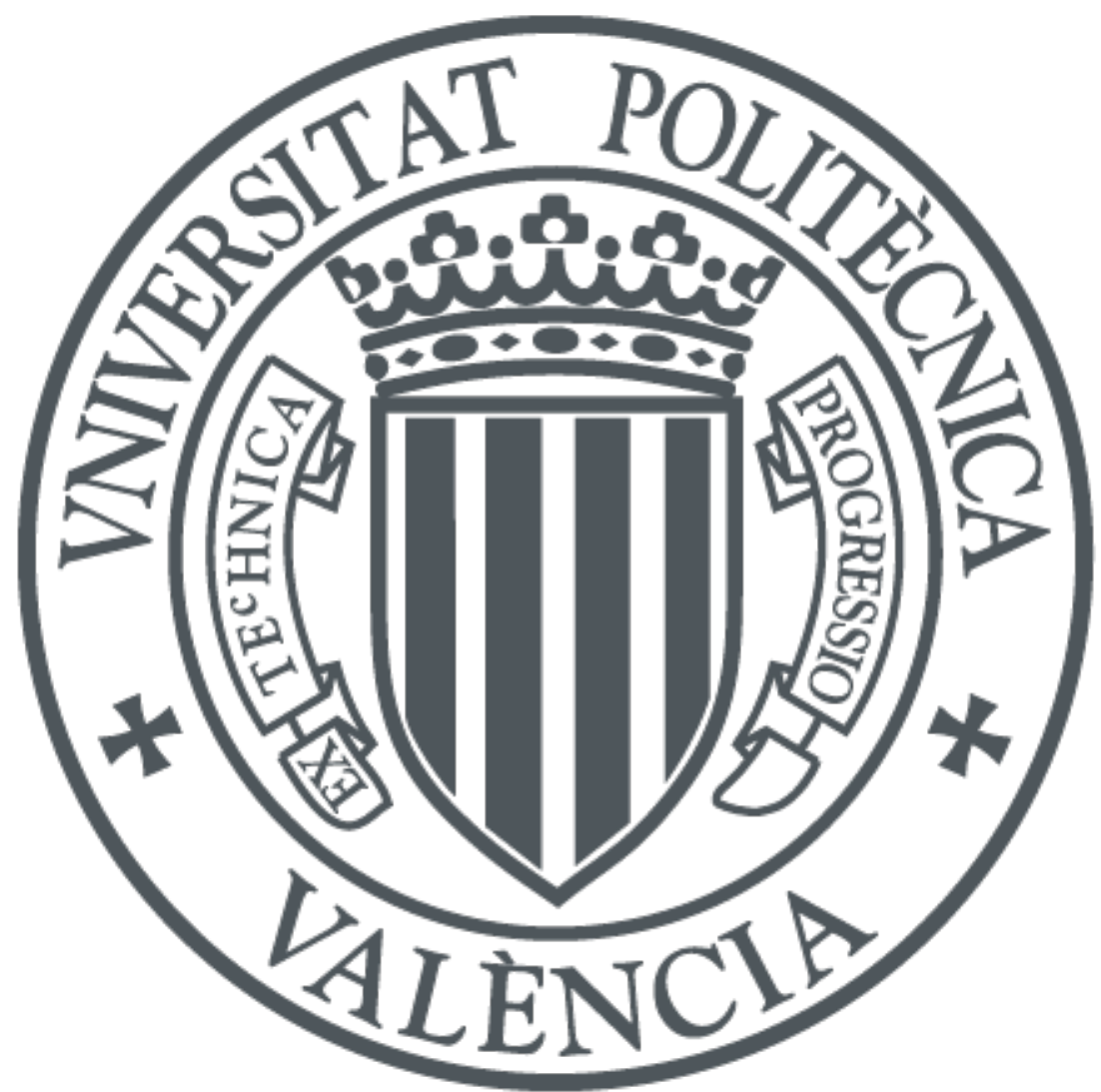

The final publication is available at

https://doi.org/10.1016/j.radphyschem.2018.08.002

Copyright Elsevier

Additional Information 


\title{
Experimental Radon Exhalation Measurements: Comparison of different techniques.
}

\author{
A. Noverques, G. Verdú, B.Juste, M. Sancho \\ Institute for Industrial, Radiophysical and Environmental Safety (ISIRYM), Universitat Politècnica de \\ València, Camino de Vera s/n 46022 Valencia (Spain) \\ Tel.: +34 963876334; Fax: +34 963877639; e-mail: gverdu@ upvnet.upv.es
}

\begin{abstract}
Radon is a gas produced from the radioactive natural disintegration of radium and uranium, which is present in soils and different building materials. Due to its gaseous nature, it emanates to the surface and penetrates both by convection and diffusion into the houses. According to recent studies, radon is considered the second leading cause of lung cancer, and it has prompted legislative changes to reduce exposure to this gas.

In Spain, the current legislation -R.D. 783/2001 Regulation on Sanitary Radiation Protection and IS-33 Instruction of the Nuclear Safety Council, establishes uniform rules for workers' health protection in radioactive installations. In 2013, the European legislation was updated with Directive 2013/59 / EURATOM which sets limit values and action plans for radon exposure for homes, public buildings and workplaces for any entrance roads (soil, building materials or water). This Directive must be incorporated before $18^{\text {th }}$ February 2018 into Spanish legislation, so it is necessary to perform, prior to that date, appropriate protocol techniques and methodologies for the measurement radon concentrations in air. This work aims at a preventive approach to the situation. That is, to measure the concentration levels of radon exhaled prior to the design and construction of the dwellings to avoid their accumulation inside

The main purpose of this work is the comparison of different radon exhalation measurement techniques in order to define the most appropriate methodology in different cases for the implementation of the new radon control Directive.
\end{abstract}

Keywords: radon, exhalation, surface emission chamber, electret, soil gas probe, charcoal canister

\section{Introduction}

In 1984 the existence of high concentrations of radon inside the houses was discovered. From then on, the concern about radon and its effect on health grew until the World Health Organization (WHO) considered it as a carcinogen element in 2010. Two of the radon's daughters, Po-218 and Po-214 are in solid state and bind to air particles, so they can be deposited in the lungs in the inhalation process. Radon is responsible for 3 to $14 \%$ of lung cancer deaths, the leading cause of lung cancer in non-smokers (WHO, 2009)

Although radon does not usually have high levels of air concentration, it tends to accumulate in dwellings, resulting in very high concentrations, in areas with very permeable soils or with high radium content. In 2013, the EU Official Review published Directive 59/EURATOM, which established limit values and action plans for radon exposure in homes, buildings and workplaces, reducing existing reference values. This directive must be incorporated before February 18, 2018 into the Spanish legislation. However, existing and future legislation refers to concentrations of radon in air but not to radon exhalation.

At the moment there are few studies that focus on the development of methodologies for the measurement of radon exhalation.

This work supposes a preventive approach of the situation, that is to say, it tries to anticipate to the legislation to measure radon before the design of the houses and to avoid the accumulation in the houses.

1.1. Radon exhalation

It is important to differentiate the steps of the radon release procedure into the atmosphere. The possible emission of Rn to the atmosphere can be produced according these processes:

- Emanation: the radon atoms escape from the grains in the interstitial space between them. This process will depend on the radio concentration and grain size.

- Exhalation: the radon atoms transported to the soil surface are exhaled to the atmosphere. 
There are several methods for measuring radon which is generally based on the measurement of their alpha daughters or the gamma emissions of some of them. These methods of measurement are divided into passive methods, where post-exposure analysis are required or active methods when a direct reading of radon levels is obtained.

Most techniques are used to know the concentrations of radon in air and to a lesser extent radon in water or exhaled radon.

The objectives of this work are:

- Development of different methodologies for the measurement of Radon 222 exhalation in order to define the procedure and conditions of application of each of the techniques before the entry into force of Directive 2013/50 / Euratom.

- Selection and definition of the most suitable protocol for measurement of radon exhalation.

\section{Materials and methods}

\subsection{Selection placements for measurements}

Three different locations were selected for radon exhalation measurements:

a) Background measurements

Measures were taken in the gardens of the Universitat Politècnica de València location where the rate of exhalation is known to be at the level of the radioactive background. These measurements where used to check the techniques studied.

b) Controlled radon activity measurements

A device has been developed which consists of a tank, filled with earth inside, with a pitchblende stone at the bottom inside. The objective of this scenario is to perform measurements in the absence of the influence of external factors such as climatology.

\section{c) Field measurements}

Subsequently, a site in the Comunitat Valenciana in which there is a significant amount of radon was selected to perform measurements. The site selected has been the Marjal of Peñíscola (a marsh in Castellón, 40.37332N - 0.402306E), a wet zone of confluence of waters from different sources where diverse aquatic species of environmental interest can be found. The urban projects, which have caused the degradation of the wetland, the high density of population and the overexploitation of water are some of the possible causes of the increase of the amount of radon in the marsh, according to previous studies carried out by Vicente Moreno et al. (2008).Therefore, in order to perform a detailed and exhaustive study of the characteristics of each of the radon exhalation measurement techniques, experimental measurements were made at that location.

\subsection{Selected techniques for radon exhalation measurements}

Depending on the various selection criteria and the variety of radon measurement methods, the following techniques have been selected: soil gas probe, surface emission chamber, electret $\mathrm{H}$ chamber and activated charcoal cánister.

a) The soil gas probe measures the radon gas emanation from the alpha daughters, through the energy spectrum given by the RAD7 detection monitor. The duration of the measurement is 20 minutes plus the purge and cleaning time of the probe. The concentrations of radon emanated are obtained in $\mathrm{Bq} / \mathrm{m}^{3}$. This technique of measurement of radon emanation allows making a previous screening to know the existence or absence of radon in a location. For the field measurements it is very useful to know quickly the possibility of finding radon before measuring the exhalation of the soil that requires greater times.

b) Surface emission chamber, measures the exhalation of radon through the accumulation of gas inside the chamber. It measures the alpha daughters of radon through the spectrum of energies given by the RAD7 detection monitor. The duration of the measurement is 3 hours plus the purge time and the cleaning time. 
The Equation 1 is used to determine the rate of exhalation from the measurement obtained with this technique. According to the norm UNE-EN ISO 11665-7:

$$
E=S L \cdot \frac{V}{S}
$$

Where SLis the slope of the line that is obtained during the accumulation process of radon inside the chamber, which relates the volumetric activity $\left(\mathrm{Bq} / \mathrm{m}^{3}\right)$ and the exposure time, $\left(\mathrm{Bq} / \mathrm{m}^{3} / \mathrm{hr}\right), V$ is the chamber volume $\left(\mathrm{m}^{3}\right)$ and $S$ the chamber surface $\left(\mathrm{m}^{2}\right)$.

c) H-chamber connected to an electret. It allows knowing the level of exhaled radon from the accumulation of the gas inside. The electret is charged positively and the negative ions produced in the decay of the radon discharge it during the 6 hours of measurement.

To obtain the rate of exhalation by this technique the expression has been developed by the authors and corresponds to Equation 2:

$$
E=\frac{V \cdot \lambda \cdot 2 * C_{R n}}{S \cdot(1-\exp (-\lambda \cdot t))}
$$

Where $V$ is the chamber volume $\left(\mathrm{m}^{3}\right), \lambda$ the decay constant $\left(\mathrm{hr}^{-1}\right), C_{R n}$ the radon concentration $\left(\mathrm{Bq} / \mathrm{m}^{3}\right), S$ the chamber surface $\left(\mathrm{m}^{2}\right)$ and $t$ the exposure measurement time (hr).

d) Active charcoal canister. It is based on the passive adsorption of radon on the surface of the carbon granules. This technique provides reliable results in a few days (normally 3 days). The canister has been covered with a high radon non-radon-permeable container to achieve accumulation therein during the given period and it is analyzed by gamma spectrometry using a scintillation detector

The concentration of radon gas is determined from its descendants, $\mathrm{Pb} 214$ and Bi214 whose gamma peaks at 242, 294, 352 and $609 \mathrm{KeV}$ are obtained by placing the sealed vessel above the NaI detector. Due to the superposition of the three low energy peaks, only two regions are necessary of interest (ROI): from 220 to $396 \mathrm{keV}$ and from 565 to $655 \mathrm{keV}$, approximately as it is shown at Fig. 1

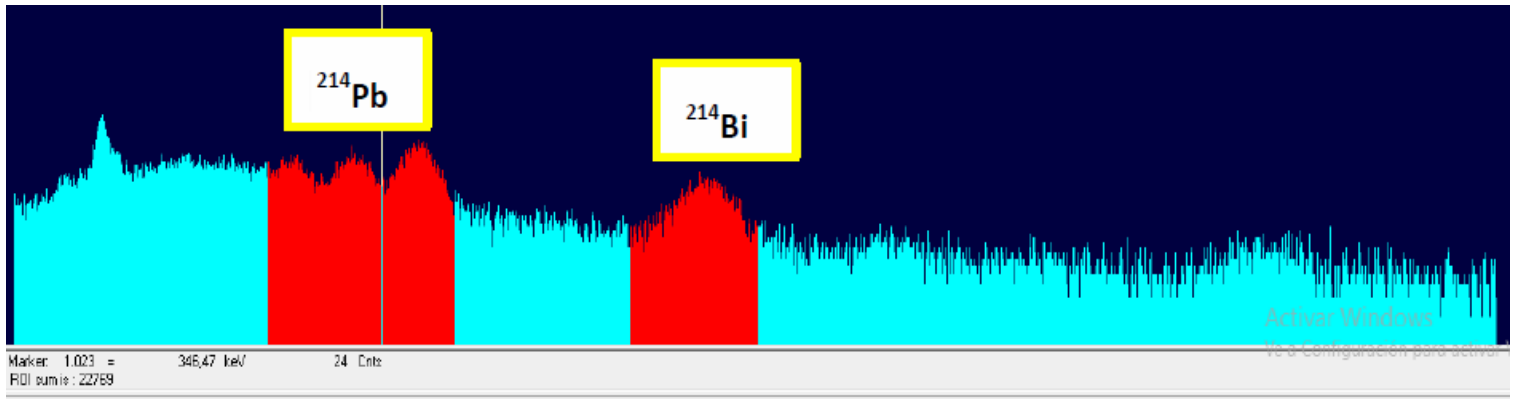

Fig. 1. Gammaspetrometry (GammaVision, 2017)

Considering the counts obtained from the regions of interest, and subtracting the background level (in counts values), also considering periods of exposure and the moisture abstraction coefficient, the radon co-concentration could be calculated. Radon concentration values obtained allows later to obtain the radon exhalation rate.

The expression to calculate exhalation rate has been developed by the authors and corresponds to the Equation 3.

$$
E=\frac{V \cdot \lambda \cdot 2 * C_{R n}}{S_{\text {efectiva }} / 0.24}
$$

Where $V$ is the chamber volume, $\left(\mathrm{m}^{3}\right), \lambda$ the decay radon constant $\left(\mathrm{hr}^{-1}\right), C_{R n}$ the radon concentration $\left(\mathrm{Bq} / \mathrm{m}^{3}\right)$, y $S_{\text {efective }}$ the exhalation surface $\left(\mathrm{m}^{2}\right)$ by the Equation 4.

$$
S_{\text {efective }}=S_{\text {chamber }}-S_{\text {canister }}
$$




\section{Results and discussion}

\subsection{Measurements by the emanation soil gas probe}

The emanation probe measurements have been made at the three proposed locations: background levels, controlled radon activity levels and field measurements.

Measurements in the placement of background levels have used to check the instrumentation. In addition, background values have been verified, according to the levels of exhalation rate established for the Comunitat Valenciana, at the UPV.

The emanation probe allows a screening of the field measurements. It allows knowing in just 30 minutes the existence of radon gas in one location. However, to measure the exhalation rate, longer measurement times are required.

Obstructions have been observed at the lower end of the probe after each measurement. It is recommended for efficient use of the probe to clean, after each measurement, the radon suction holes emanated by a smaller device to remove soil and vegetation that may be inserted into the probe.

\subsection{Results of radon exhalation}

\subsubsection{Analysis of exhalation measurements}

In this section we have performed the analysis of the different exhalation techniques in terms of location. For background measurements, the results have been obtained in the Fig. 2.

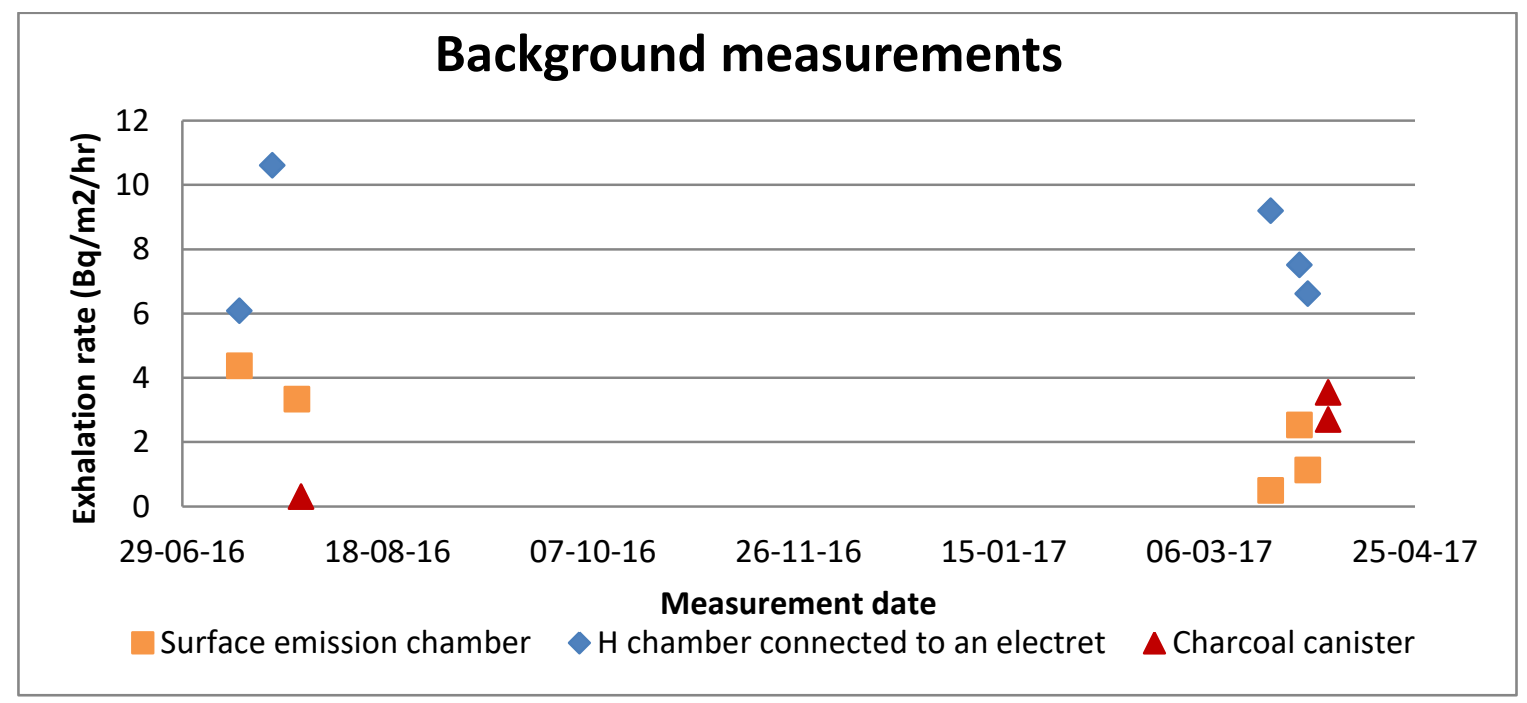

Fig. 2. Background measurements for radon exhalation using the three selected techniques

The rate of exhalation calculated from the concentration of radon shows similar orders of magnitude, in all cases within the range of expected background values.

For controlled measurements, the obtained results are shown in Fig. 3. 


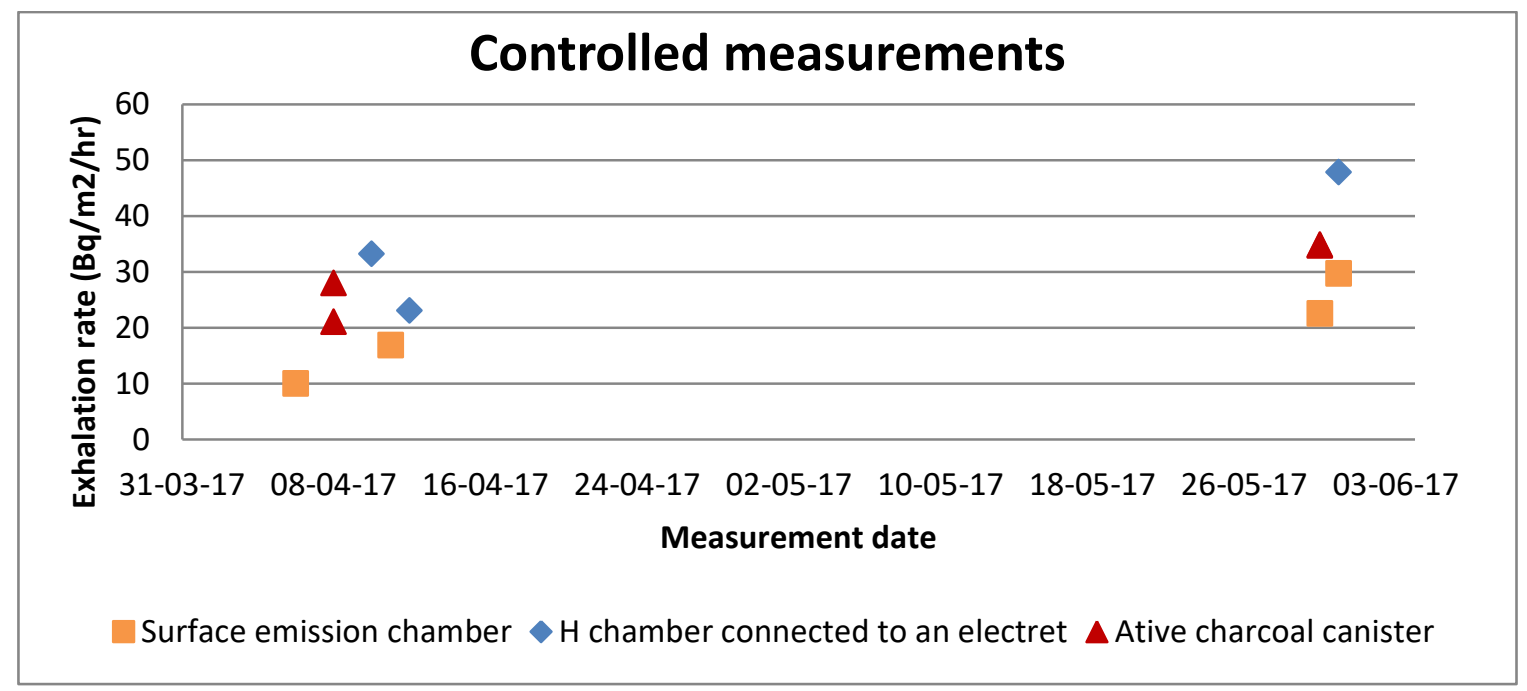

Fig. 3. Exhalation rate results for controlled radioactivity.

This location has allowed measurements without the influence of weather conditions. In this case, the obtained exhalation rate results are similar for values of substantially equal radon concentrations. However, results during May were higher than the obtained in April due to the ventilation of the room where the device was located, Since, for internal organizational reasons, during April the ventilation was higher than in May. It shows the good reproducibility of the techniques in the tank and the validation of the measurement procedures.

For Peñíscola marsh measurements, the results are shown at Fig. 4.

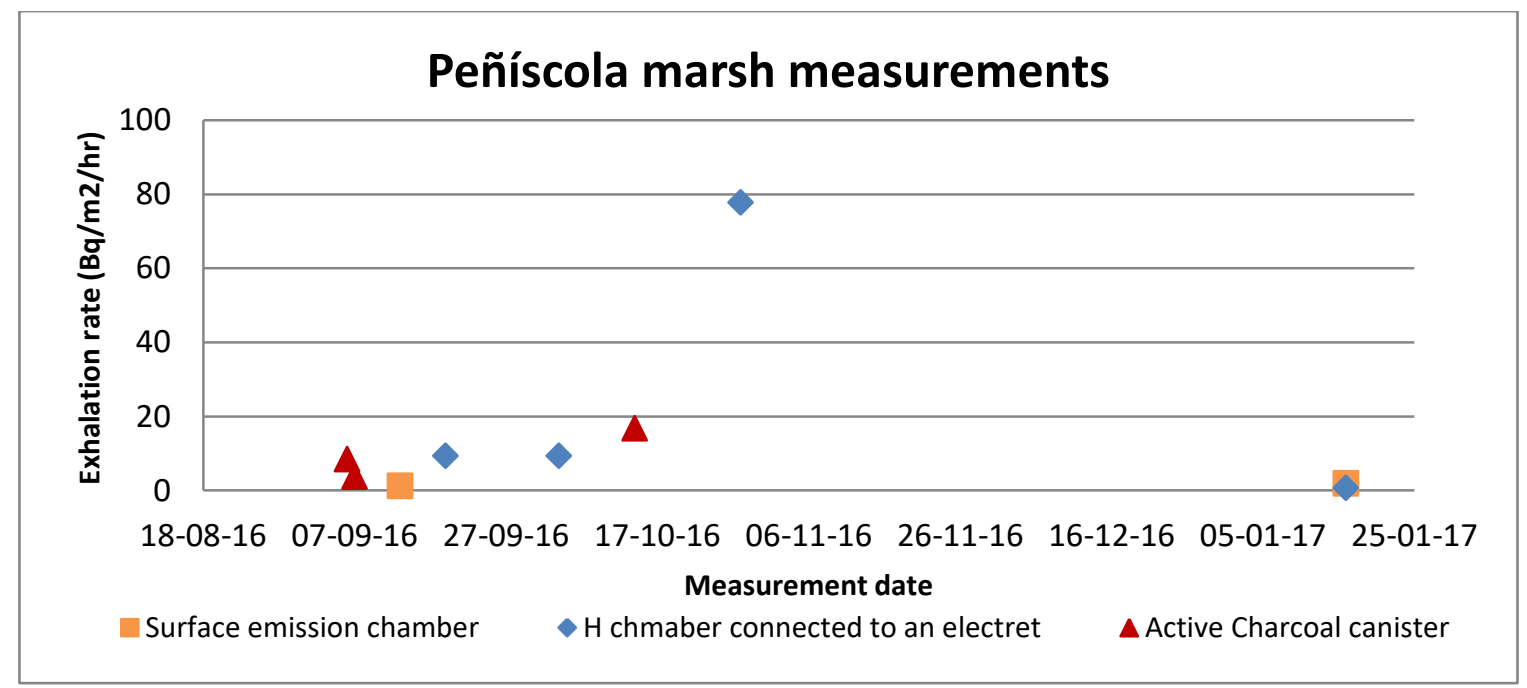

Fig. 4. Results of field exhalation rate in different locations within the Peñíscola marsh.

The results of exhalation rate obtained in this situation are lower than expected in almost all measurement points in the Marsh. Measurements at this location are influenced by weather conditions (mainly temperature and humidity), and soil characteristics at each point of the location. One of the points of greatest exhalation rate measured corresponds to the point where the concentration of radon emanated was higher in part because of high temperatures. Therefore, the exhalation rate expressions developed have been applied efficiently.

From the field measurements have been possible to develop the improvement proposals that allow an increase in the performance and efficiency of the measurement techniques. 


\subsubsection{Assessment of exhalation techniques}

The following Table 1 shows the main characteristics of each radon exhalation measurement technique, the difficulties observed in its measurement and the improvements proposed in each case.

Table 1. Radon exhalation techniques

\begin{tabular}{|c|c|c|c|c|}
\hline $\begin{array}{l}\text { Exhalation } \\
\text { techniques }\end{array}$ & $\begin{array}{c}\text { Measurement } \\
\text { duration }\end{array}$ & Cost & Difficulties & Improvement proposals \\
\hline \multirow[t]{2}{*}{$\begin{array}{l}\text { Surface emission } \\
\text { chamber }\end{array}$} & \multirow[t]{2}{*}{3 hours } & \multirow[t]{2}{*}{ High } & Leak tightness & $\begin{array}{l}\text { - Create a new chamber that } \\
\text { covers the surface emission } \\
\text { chamber. } \\
\text { - Modify chamber geometry }\end{array}$ \\
\hline & & & $\begin{array}{l}\text { Difficult insertion in } \\
\text { soil }\end{array}$ & $\begin{array}{l}\text { Improve the insertion device } \\
\text { in the soil }\end{array}$ \\
\hline $\begin{array}{c}\text { H Chamber } \\
\text { connected to an } \\
\text { electret }\end{array}$ & $6-8$ hours & Low & Long measurement time & Decrease measurement time \\
\hline \multirow{3}{*}{$\begin{array}{l}\text { Active charcoal } \\
\text { canister }\end{array}$} & \multirow{3}{*}{3 days } & \multirow{3}{*}{ Medium } & $\begin{array}{l}\text { Difficult insertion in } \\
\text { soil }\end{array}$ & $\begin{array}{l}\text { Improve the insertion device } \\
\text { in the soil }\end{array}$ \\
\hline & & & $\begin{array}{l}\text { Reduced exhalation } \\
\text { surface }\end{array}$ & $\begin{array}{l}\text { Create a new device that } \\
\text { allows lifting of the canister } \\
\text { and changing its position }\end{array}$ \\
\hline & & & Long measurement time & Decrease measurement time \\
\hline
\end{tabular}

The Table 1 shows the techniques used in measuring radon exhalation according to the measurement times, their cost, and the difficulties encountered from their use and its proposed improvements. Depending on all these variables, the selected technique to measure radon exhalation is the $\mathrm{H}$ chamber connected to an electret. This chamber is a simple method; it presents the lower cost, greater sealing and a good insertion in the floor. The improvements requires to use the $\mathrm{H}$ chamber are reduced.

\section{Conclusions}

Due to the incorporation of Directive 59/EURATOM into Spanish legislation before February 2018, a procedure has been developed for the measurement of radon exhalation using various techniques.

The soil gas probe, allows to measure the emanation of radon gas. It is a fast method (20 minutes of measurement) and simple to use. This technique allows a screening of each zone to know if there are high concentrations of radon in the soil or not.

The surface emission chamber, the $\mathrm{H}$ chamber connected to an electret and the active carbon canister covered with a radon-impermeable chamber allow the exhalation rate to be accurately known through the accumulation of radon in the interior. Thanks to the three accumulation chambers similar exhalation rate values were obtained, so that the expressions developed and the operation of the chambers could be validated.

Depending on the duration, cost, difficulties encountered and proposed improvement, the most appropriate technique for measuring radon exhalation is the $\mathrm{H}$-chamber connected to an electret. The $\mathrm{H}-$ chamber connected to an electret presents greater robustness and air tightness, a better insertion device and a lower cost. 


\section{Acknowledgements}

Authors would like to express their gratitute to people from the Chemical and Nuclear Engineering Department and the Environmental Radioactivity Laboratory of the Polytechnic University of Valencia.

\section{Referencs}

Directive 2013/59/Euratom of 5 December 2013 - Protection against ionising radiation laying down basic safety standards for protection against the dangers arising from exposure to ionising radiation.

Medición de la radiactividad en el ambiente. Aire: radón-222. Parte 1: Orígenes del radón y sus productos de desintegración de vida corta y métodos de medición asociados. (ISO 11665-1:2012).

Medición de la radiactividad en el ambiente. Aire: radón-222. Parte 7: Método de acumulación para estimar la tasa de exhalación en superficie. (ISO 11665-7:2012).

Moreno,V., Cherta, A., Rodellas, V., García-Solana, E., García-Orellana, J., Baixeras, C. Resultados preliminares de los niveles de radón en la Marjal de Peñíscola. Grup de Física de les Radiacion.s Departamen de Física. Universitat Autònoma de Barcelona.

Wang, N., Xiao, L., Li, C., Mei, W., Hang, Y., Liu, D.(2009). Level or radon exhalation rate from soil in some sedimentary and granite areas in China. Journal of Nuclear Science and Techonology, 46:3, 303-309. 